\title{
LOS CLUBES REGIONALES DE LIMA VISTOS COMO ELEMENTOS DE CONSERVACIÓN Y DIFUSIÓN DEL FOLCLOR NACIONAL PARA EL CONSUMO TURÍSTICO
}

\section{LIMA REGIONAL CLUBS SEEN AS ELEMENTS OF CONSERVATION AND DIFFUSION OF NATIONAL FOLKLORE FOR TOURISM CONSUMPTION}

\author{
Gloria Olivera Alegre \\ Universidad de San Martín de Porres, Perú
}

\section{RESUMEN}

La ciudad de Lima durante mucho tiempo fue una ciudad de paso hacia el Cusco y Machu Picchu, no se le reconocían suficientes atractivos turísticos aparte del Centro Histórico de Lima capaces de retener al turista internacional unos días más en esta ciudad. En este trabajo se ha tratado de hurgar en una posibilidad de interés turístico que se ha mantenido latente durante décadas pero al margen del involucramiento con esta industria. La población migrante al verse obligada a vivir en Lima vio como un canal de emergencia social a la asociación de coterráneos que se tradujo en clubes departamentales, provinciales y distritales. Estos clubes se convirtieron en un soporte existencial pero a la vez en un «cofre» para conservar la cultura folk rural regional. Estas tradiciones podrían ser un producto nuevo de interés turístico recreativo - cultural que puede tener una demanda.

Palabras clave: Coterráneos, clubes departamentales, cofre, cultura folk, demanda.

\begin{abstract}
Lima has long been a city of Cusco and step towards Machu Picchu, you will not recognize enough attractions apart from the Historic Center of Lima, able to retain the international tourist few days in this city. This paper has tried to delve into the possibility of interest that has remained dormant for decades but the margin of involvement with the industry. The migrant when forced to live in Lima population saw as a social channel to the association of fellow countrymen which resulted in departmental, provincial and district emergency clubs. These clubs became an existential support but also in a «box» to preserve regional culture rural folk. These traditions could be a new product of recreational and cultural attractions that may have a claim.
\end{abstract}

Keywords: Coterraneos, departmental clubs, chest, folk culture, demand 


\section{Introducción}

La ciudad de Lima tiene varios escenarios en su realidad territorial que se pueden proyectar como futuros atractivos turísticos. Nos ocuparemos de uno de ellos, se trata de los clubes regionales, sobre este tema veremos los aspectos teóricos del folclor, del turismo cultural y de los clubes considerándolos como emporios de la tradición anónima de los pueblos a los cuales representan.

Se trata de demostrar que los clubes regionales tienen un potencial en el aspecto turísticos - cultural más o menos desarrollado, sin constituir aun en la mayoría de los casos, establecimientos que puedan atraer cantidades significativas de turistas nacionales y extranjeros debido a varios factores.

Los factores que pueden ser los responsables de la poca afluencia de turistas a estos establecimientos pueden ser internos y externos. Los factores internos están referidos a la administración de los clubes, entre ellos el interés de sus directivos dirigido exclusivamente a sus socios y simpatizantes. Los factores externos están vinculados a la inexistente valoración que actualmente dan a estos establecimientos los responsables estatales y empresas privadas de la difusión del patrimonio turístico que posee la ciudad de Lima, quizás por falta de estudios concretos.

\section{Los clubes regionales y el turismo vistos como componentes de un fenómeno sociocultural}

En este estudio centraremos al turismo como un fenómeno sociocultural, porque permite una reflexión más precisa en relación con las actividades que ofrecen los clubes departamentales, provinciales, distritales; y regionales que son distintas denominaciones según se trate de las dimensiones físicas de los territorios, o áreas culturales o división política, pero todos los clubes tienen características similares en cuanto cultivan la fraternidad, el compadrazgo, la ayuda mutua, propician el encuentro entre coterráneos, buscan revivir las tradiciones propias de sus lugares de origen: música, gastronomía, fiestas religiosas y en general todo lo referido al folclor. En adelante llamaremos simplemente clubes regionales a todas estas instituciones sociales y culturales de carácter tradicional y provinciano.

Los clubes regionales de la ciudad de Lima, se fundan para que una determinada comunidad se sumerja en su propia tradición, la conserve y sea su razón de ser y muestre en vivo parte de nuestra identidad.

Jorge Muelle nos da la siguiente definición: «El folk es el pueblo con cultura tradicional. Mildred Merino de Zela identifica el folk con la cultura rural mientras que la cultura urbana o citadina es aquella que tiene el dominio de la «civilización» (occidental) (Merino, 2003).

Desde el punto de vista sociocultural, Graburn, (1976 b, cit. en Fuller, 2004) dice que el turismo es un ritual secular y en muchas sociedades contemporáneas cumple funciones que fueron sagradas en la antigüedad.

Para las sociedades humanas es una necesidad de su naturaleza, alternar entre lo sagrado y lo profano; entre lo cotidiano y lo extraordinario por la necesidad de separar aquello que es opuesto a otro y así distinguir sus contenidos. 
Entendemos por ritual todo aquello que pertenece al rito, es decir, costumbres o conjunto de ceremonias de reglas establecidas que antiguamente servían solo para referirse al culto y ceremonias religiosas. El ser humano necesariamente comparte su vida entre lo profano y lo sagrado y además otras características comunes sobre su actuar que pueden ser explicadas mediante la teoría de los universales y los contenidos que encierra la definición de cultura.

Los Universales de la Cultura, (Herkovits, 1958), es una teoría antropológica que propone que toda la humanidad tiene doce formas básicas de hacer cultura o sea inventar a partir de lo que la naturaleza le ofrece, cualquiera que sea la geografía de la población o su nivel cultural e incluye, por lo tanto, desde las comunidades más primitivas que existieron en la tierra hasta las naciones actuales más avanzadas.

«Cultura es un conjunto de formas y modos adquiridos según la manera de concebir el mundo, de pensar, de expresarse, percibir, comportarse, organizarse socialmente, comunicarse, sentir y valorarse a uno mismo en cuanto individuo y en cuanto a grupo. Es intrínseco a las culturas el hallarse en un constante proceso de cambio» (Heise, citado en Tubino y Ardito, 2000).

Una característica primordial de la teoría de los Universales es la herencia cultural, la cual nos dice que los conocimientos adquiridos se van acumulando generación tras generación al principio a través del ejemplo, la experiencia, la viva voz y la enseñanza; y con el tiempo esta herencia se va ampliando por el uso de otros instrumentos más sofisticados.

Estos universales son el lenguaje, la magia y la religión, la recreación, la medicina, el derecho, la política, la arquitectura, el folclor, la ciencia y la tecnología, la economía, el arte, la filosofía.

No es extraño que el hombre a causa de estos dones genéticos y su capacidad de aprendizaje, sea un gran viajero desde los inicios de nuestra humanidad con fines de subsistencia, también de peregrinación o por la curiosidad de conocer otras costumbres, buscar conocimientos, intercambios comerciales y sobre todo por la necesidad de despegarse de su entorno para recrearse o renovarse.

De estas ideas se puede espontáneamente evocar algunas tipologías del turismo (turismo religioso, esotérico, de aventura, de negocios, tradicional, etc.).

\section{El turismo y la cultura}

El turismo es visto actualmente como un componente o forma de la recreación (universal de la cultura) y se puede definir como el traslado de personas de un lugar a otro con fines principalmente de descanso por un tiempo determinado.

En la antigüedad como en nuestros tiempos, las peregrinaciones siguen haciéndose, un sector significativo de los viajeros se dirige a los lugares que se consideran santos según las creencias de las distintas grandes religiones actuales o también se encaminan hacia lugares «esotéricos» donde se concentran energías invisibles saludables. Estos lugares los suelen ubicar muchas veces en zonas arqueológicas. 
Siguiendo a Graburn, un viaje implica a veces un cambio dramático o una inversión de la vida diaria por un tiempo determinado, por ejemplo: el gasto por el ahorro, la diversión por el trabajo, la desinhibición por la formalidad, lo exótico por lo cotidiano. El salir de su sociedad implica una suspensión del control social porque en el destino escogido se vuelve anónimo, no lo conocen y su comportamiento está libre de las reglas que debe guardar en su comunidad.

El viajar para hacer turismo implica el «tránsito» hacia la «inversión». Es un ritual de pasaje que presenta las siguientes características:

- $\quad$ Presenta un periodo de cambio.

- El ritual tiene un límite y hay un reingreso a lo cotidiano.

- El periodo de tránsito cambia lo cotidiano: puede involucrar cambios radicales, p. ej., alimentación habitual por ayunos, conversación coloquial por cánticos propiciatorios, o también, alimentarse con potajes exóticos y dedicarse a conversaciones con contenidos novedosos o superfluos.

- El viaje ejerce influencia en las actitudes frente al mismo objeto en una forma leve hasta una forma profunda según sea la intensidad de la experiencia y otras circunstancias.

En el ritual de pasaje se pueden distinguir claramente tres periodos o etapas obligatorias:

1. La separación o alejamiento del lugar de origen, lo que implica romper temporalmente con la estancia habitual.

2. Limbinal, que es el espacio de tiempo en que se hace el cambio de vida (permanencia en el destino) donde se hace el quiebre a la cotidianidad a veces con experiencias de gran intensidad y una conducta más libre por la falta del control social.

3. Reincorporación al orden habitual, esta significa renovar los vínculos con la propia sociedad.

\begin{tabular}{ccc}
\hline & RITUAL DE PASAJE O VIAJE \\
\hline Separación/del/lugar/de/origen & $\begin{array}{c}\text { Limbinal } \\
\text { Cambio de vida }\end{array}$ & Reincorporación hacia el orden habitual \\
1 & 2 & 3 \\
(EMISOR) & & (DESTINO) \\
\hline
\end{tabular}

Elaboración propia 
La permanencia en el destino (2) implica nuevas necesidades y una incertidumbre acompañada de una vulnerabilidad frente a lo desconocido. Las necesidades básicas tienen que ser cubiertas en el nuevo destino, para permanecer en la estancia y para regresar a lo habitual y cotidiano, por ello se dan una variada gama de servicios desde los tiempos de los que se tiene memoria y que pueden remontarse a Egipto (4000 a. C.).

Estos servicios no solo debían ser de subsistencia y alojamiento, también hacían falta guías, un conocimiento de las costumbres, economía del lugar de destino. Entre la gran variedad de establecimientos se podría mencionar aquellos que fueron creados por asociación de gentes de una región determinada y que ofrecían sus propias preparaciones y su propio folclor.

El viajero consume esta gran variedad de servicios y espera que sean placenteros aunque sean efímeros en parte. «Lo efímero es la expresión de un acto instantáneo que no tiene futuro, nace y muere en el presente» (Urbano, 2004, p. 19).

La permanencia en el lugar de destino pondrá al viajero en situaciones de nuevas experiencias quizás imaginadas pero al hacerse reales si son lo suficientemente placenteras le harán olvidar el pasado y centrarse en el consumo aunque sea efímero.

\section{Las migraciones y el origen de los clubes regionales}

Bordiu al definir el concepto de reproducción ligado al tema cultural, argumenta que las diferentes actividades que el ser humano desarrolla están conectadas a formas simbólicas como instrumento de dominación y poder donde los «sistemas simbólicos cumplen su función política de instrumentos de imposición o de legitimación de la (...) dominación de una clase sobre otra» (1997, citado en Tito, 2010). La escuela y la familia vendrían a ser los principales centros de reproducción.

La familia asume un papel determinante en el mantenimiento del orden social, en la reproducción no solo biológica sino social, es decir, en la reproducción de la estructura del espacio social y de las relaciones interpersonales. La dominación del padre o de la madre es por el poder económico, es o son los alimentadores de la prole.

El Estado asume su papel dominante cuando interviene poniendo escuelas en las zonas marginales por intereses políticos, por promesas en las elecciones. Las escuelas incorporan a los niños y jóvenes al quehacer citadino.

El migrante de la sierra o de la selva cuando llega de su comunidad de origen adopta elementos culturales de la ciudad que se le presentan y que requiere para supervivir. El proceso de adopción tiene diferente graduación según sea mayor o menor la endoculturalización y el aprecio por su cultura de origen, de allí surgirá una más o menos resistencia al cambio. El sentimiento de añoranza lo lleva a tomar acciones concretas: escuchar la música tradicional de su región, continuar con la dieta a la que está acostumbrado, buscar la compañía de los coterráneos, seguir hablando el dialecto que aprendió de niño. 
Este fenómeno cultural de resistencia al cambio dará origen a la expansión de la cultura tradicional fuera de su lugar de origen, o también a un repliegue o tal vez a una hibridación en algunos aspectos pero manteniendo la esencia o el espíritu de la tradición.

Al manifestar los hechos culturales en la cotidianidad y estar inmersos y conectados a todo un sistema de poder constituyen una forma de reproducción sujeta a reglas de juego que se ejercen como mecanismos de control social. Por ello, los migrantes continúan reproduciendo la variedad de música, comidas, festividades, creencias, vestidos, formas de vivienda, costumbres que practicaban en sus zonas de origen y que a medida que pasen los años la adaptación al medio hará que se redefinen, se adapten. Ante este peligro y con el fin de conservar la pureza de su cultural primigenia, puede darse el mecanismo de la asociación ya sea en recreos, centros musicales o clubes regionales.

Merino (2003) en su artículo Hacia una teoría del Folklore Peruano, hace notar que:

El hecho folclórico debe cumplir una finalidad (...) satisfacer una necesidad, (espiritual o material, estética en general; recreativa, de distensión espiritual, alivio del subconciente, etc); y poseer una aplicación práctica (realizar una faena, estimular el trabajo, aunar voluntades para el trabajo en común, iniciar noviazgos, establecer vínculos de parentesco como el compadrazgo, etc. (p. 64)

La fundación de instituciones para reproducir el folclor tradicional merece un estudio minucioso, los primeros clubes tienen una antigüedad superior a las migraciones masivas, los clubes Lambayeque, Arequipa, Huancayo, Ancash están entre los 80 hasta 60 años de antigüedad, sus fundaciones no coinciden con las grandes migraciones de Ayacucho, Huancavelica, Junín.

Estos clubes de fundación antigua tienen sus locales en zonas residenciales de la ciudad de Lima y fueron fundados por personajes de sus provincias. Se trata del mismo espíritu: conservar el folclor de sus lugares de origen, sea fundado por notables de una región o por pobladores venidos a Lima por la aparición de la violencia en los pueblos de la sierra.

Podría parecer simple afirmar que el espíritu provinciano se puede mantener entero a pesar de hallarse fuera de su localidad y no lo es porque la aculturación es un proceso ineludible y está en permanente dinamismo. «Los procesos socioculturales se combinan para generar nuevas estructuras y por lo tanto no pueden ser considerados hechos puros, son hibridaciones» (Albo, 2002, citado en Tito, 2010).

La hibridación es un proceso de cambio continuo donde los elementos culturales se mezclan, se integran, se adaptan constantemente. La hibridación es sinónimo de mestizo.

La producción, reproducción y transformación de las prácticas culturales mantienen su propia dinámica interna que se desarrolla en diferentes formas y niveles de gradación, según los contextos culturales donde se desplieguen. 


\section{Los clubes regionales y los viajeros}

El Reglamento de los clubes departamentales especifica en el Art. 6 inciso «b», que unos de los fines de los clubes es cultivar los sentimientos de unión, solidaridad y respeto mutuo llevando a cabo actividades culturales, sociales, deportivas y recreacionales. En el inciso «e» promover el turismo sostenible hacia sus pueblos de origen y difundir su gastronomía tradicional.

Esta reglamentación vigente menciona actividades específicas y también su relación con el turismo como medio para incentivar o promover la visita de las comarcas que los clubes representan.

Actualmente, estas instituciones sociales, culturales y promotoras del turismo tienen en común el servicio diario de restauración con comidas y bebidas típicas de sus representadas. Aparte, tienen un día central de celebración y otras fiestas regionales, además de celebraciones generales como fiestas de Año Nuevo, Día de la Madre entre otros acontecimientos anuales.

La participación de los turistas y visitantes nacionales como consumidores de las actividades que ofrecen estos establecimientos regionales, es actualmente una oportunidad de cumplir con los fines del Reglamento, dándole un incentivo comercial porque las divisas que los visitantes extranjeros pueden invertir en gastronomía y recreación solo harían demandar la oferta que ya está preparada con muchos años de experiencia porque son actividades que se repiten anualmente.

Es evidente que estas instituciones pueden desempeñar una labor propiciatoria para que el turista adquiera conocimientos previos en vivo de los lugares que irá a conocer, o también rememorar el sitio original que ya vieron.

Los clubes regionales ofrecen música en vivo, gastronomía étnica en forma permanente, danzas típicas con la indumentaria original y actividades. Todo un conjunto de actividades se preparan con mucha anticipación inclusive algunas en que los visitantes foráneos pueden participar en vivo, bailando a invitación de las comparsas, apadrinando una pachamanca, aprender a hacer el ofrecimiento al Apu o a la Pachamama. El turista vería y participaría.

\section{Aspectos financieros y publicitarios sobre la apertura de los Clubes Regionales a los turistas}

Sobre la utilidad de los turistas para el mantenimiento económico de los clubes, podríamos hacernos varias preguntas: ¿Sería conveniente para los clubes, ampliar la concurrencia con turistas extranjeros por razones financieras? ¿Si los clubes promocionan la presencia de turistas en sus actividades, estas tendrían el peligro de volverse más comerciales perdiendo su autenticidad?

Sobre el aspecto publicitario nos podríamos preguntar: ¿A los clubes les convendría exhibir publicidad de ciertos productos dentro de sus recintos? ¿Qué se haría si la publicidad atrae más viajeros de los que pueden recibir? 
Actualmente, los clubes regionales mantienen sus locales y actividades sobre la base de las donaciones de sus miembros, alquiler de sus salones y patios para fiestas, reuniones sociales y banquetes, el aporte de los socios a través de cuotas mensuales y la concesión de sus restaurantes y bares. Una inyección de dinero fresco por el aumento de la concurrencia sería beneficioso para cualquier institución que ofrece servicios.

Dentro de los recintos de los clubes se exhiben y venden productos del lugar de origen como colas, golosinas y adornos. Colocar publicidad de otros similares contribuiría y serviría para despertar mayor interés por el lugar de fabricación.

Los clubes regionales son susceptibles de ser insertados en los discursos de las entidades que promueven el turismo a nivel internacional (p. ej., Guía Michelin), nacional y empresarial. Los promotores del turismo nacional como PromPerú y las empresas que operan en Lima, son instancias que buscan construir una imagen vendible de atractivos turísticos ponderando los lugares, costumbres, monumentos que poseen los lugares.

Esta maquinaria discursiva trata de producir representaciones y versiones atractivas de gran impacto en la imaginación de las poblaciones emisoras de turistas.

Las expectativas creadas en las mentes de los posibles viajeros por esta maquinaria, pueden ser cristalizadas en parte si en el circuito propuesto se introduce la visita a un club regional que representa y revalora las costumbres, folclor, gastronomía, música del sitio por visitar. Igualmente, los turistas que vienen por negocios crearán expectativas por el lugar de origen del club regional que visiten aunque por razones de tiempo y programación no vayan al lugar. Por último, quién fue al lugar que eligió puede querer repetir o afianzar la experiencia aunque sea en parte yendo al club que tiene el nombre del sitio visitado.

Las actividades que los clubes regionales realizan para cumplir sus fines dentro de sus ambientes físicos, son el producto que será consumido por los turistas y visitantes que han interiorizado en sus mentes las representaciones construidas por los encargados de vender el destino.

El manejo del mercado por los expertos hace que el producto sea asequible a los consumidores. Según Mac Cannell (1999) toda sociedad necesita acudir a sus mitos y a su estructura social, de allí surgen las conmemoraciones con desfiles militares, la edificación de estatuas, la conservación de los monumentos que traen a la mente los momentos claves de su historia y héroes que sintetizan sus ideales. La vida moderna ha hecho que se pierda este sentimiento de pertenencia pero el deseo de recuperarlo o también afianzar este sentimiento, acerca a la gente a otras culturas o a otra historia y los convierte en viajeros.

En el caso de los turistas mochileros estadounidenses bien podría tratarse de lo dicho por Mac Cannell, ellos tienen una historia reciente y escogen viajar a países como México, Perú, India, Europa que tienen culturas ancestrales con el fin de consolidar la visión un tanto difusa de la pertenencia a su país.

Los clubes regionales pueden ofrecer música en vivo, gastronomía, danzas, conmemoraciones religiosas y cívicas. Todo un conjunto de actividades se prepara sobre todo para las grandes festividades fijas de un calendario anual. 
Se puede decir que la visita a los clubes regionales es un reforzamiento de las experiencias vividas en el destino escogido, y es de una importancia superior a los videos que haya filmado o las fotos tomadas y las artesanías compradas.

Este conjunto de estímulos hará que el turista simplemente no relate su experiencia sino que pueda historiar lo vivido haciendo comparaciones, reflexiones y críticas en base al material diverso que pudo acumular.

La incorporación de los clubes a la maquinaria mercantil turística se justifica porque el turismo cultural es la principal oferta del Perú por haber sido cuna de una de las altas civilizaciones de la humanidad, y la tradición forjada a través de miles de años se mantiene con toques coloniales y actuales a través de las creaciones artísticas de los descendientes de los inmigrantes andinos afincados en Lima y en otras ciudades de la costa.

Prácticamente el club regional puede convertirse en un museo viviente, abierto donde se exhibe lo tradicional y donde los visitantes guiados por los socios del Club, que a manera de anfitriones, los sumergirán en este ambiente haciéndoles partícipes de la fiesta de manera completa y no solo mirando el espectáculo. De esta manera hay menos superficialidad, se desvanece en algo la indiferencia entre locales y foráneos.

\section{Clubes Regionales de la ciudad de Lima que están acondicionados para recibir turistas}

Se ha podido observar que los clubes de fundación más antigua ofrecen esas características y además sus locales se ubican en distritos cercanos al centro histórico de la ciudad de Lima.

Estos locales y sus actividades pueden interesar a los turistas por la facilidad del traslado, la relativa mayor seguridad, la variedad gastronómica, la autenticidad del folclor que cultivan y porque se hallan cercanos a los atractivos turísticos de la ciudad especialmente al Centro Histórico.

El variado folclor nacional está presente en todos ellos porque representan y cultivan la tradición sobre todo musical de los pueblos que representan.

Los clubes realizan sus actividades con el fin de promover la socialización entre sus miembros natos e incluyen a los simpatizantes aunque no sean de la región que representan. El ambiente humano de sus reuniones se caracteriza por la alegría del reencuentro, la espontaneidad y el calor humano.

Estos valores pueden ser apreciados claramente por los foráneos, asistir a estos locales durante sus celebraciones es una experiencia muy distinta a observar monumentos o las impersonales explicaciones de un guía durante una visita cultural.

Todas las horas invertidas en la organización de estos espectáculos dirigidos actualmente a un mercado muy restringido tienen las condiciones para atraer turistas que pasan por Lima, actualmente es un recurso turístico desperdiciado por las organizaciones turísticas del sector privado y estatales. 
La valoración de los clubes regionales puede verse desde dos aspectos diferentes: (a) las instalaciones físicas que requieren cierto confort para ser considerados como locales turísticos y (b) el contenido folclórico mismo de las representaciones y los agregados como ferias gastronómicas y artesanales, desfiles por los alrededores.

Los locales regionales en la ciudad de Lima sobrepasan la centena si contamos los clubes regionales, los provinciales, distritales y locales comerciales folclóricos en donde se presentan espectáculos y gastronomía regional, y que además realizan labores educativas y de promoción apoyando la publicación y venta de libros especializados en el lugar u organizando cursos de danzas costumbristas, preparación de bebidas y comidas, tal como también lo hacen los clubes regionales.

La selección de los clubes para este trabajo se basa en dos criterios:

- Que tengan las características de locales turísticos (equipamiento, gastronomía y actividades folclóricas), y

- Que tengan en su entorno otros lugares de índole turístico.

La selección por consiguiente fue estratificada y al azar. Los clubes seleccionados son los siguientes:

I. Club Departamental Lambayeque

II. Club Departamental Arequipa

III. Club Huancayo

IV. Club Ancash

V. Asociación Cultural Brisas del Titicaca

VI. Club Cusco

VII. Club Loreto

VIII. Asociación Centro Representativo Huari

A través de un cuadro se pondrá en forma breve parte de la información recogida de cada club estudiado que permitirá compararlos y sacar algunas conclusiones.

\section{Discusión}

Las fiestas patronales de cada club se realizan con un gran despliegue de actividades que duran todo el día, la duración promedio de las fiestas es de 10 a.m. a 10 p.m. También, se organizan otras festividades menores permanentes que tienen contenidos de gran interés por sus características originales y novedosas para el espectador foráneo. 
BREVE DESCRIPCIÓN DE LOS CLUBES REGIONALES SELECCIONADOS PARA LA MUESTRA

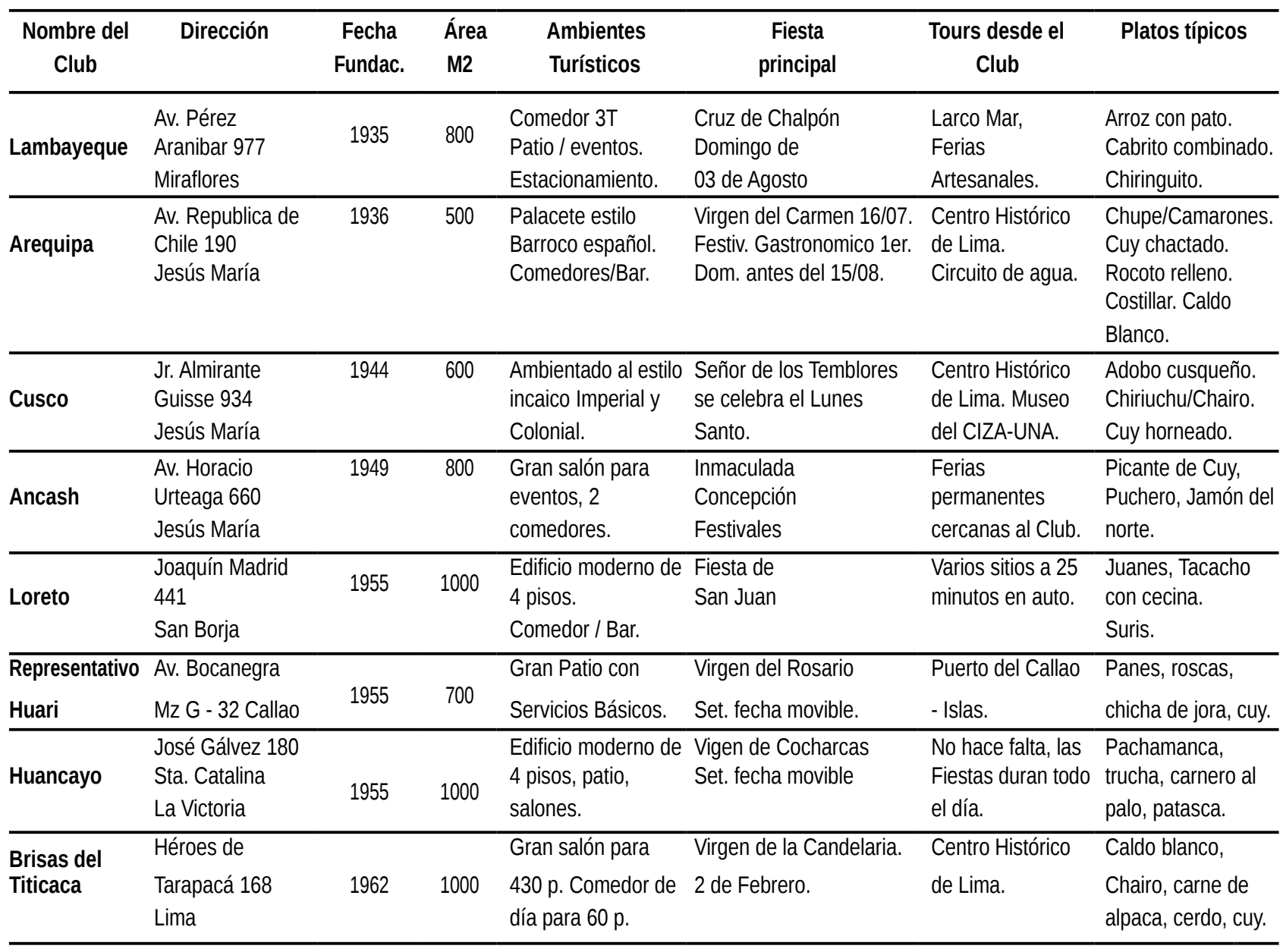

Un estudio que incluya otros clubes que cuenten con características similares a los ya vistos tanto en la calidad de los espectáculos, seguridad en la zona donde se encuentren los locales, instalaciones y comedor que puedan ser categorizados por lo menos en dos tenedores, permitiría confeccionar una guía o calendario de fiestas étnicas capaz de despertar el interés por su originalidad y calidad.

La confección de una guía o calendario en función de las fiestas de los clubes puede ser de utilidad por su contenido turístico, porque de esa manera:

- La ciudad de Lima podría contar con un nuevo atractivo que no solo permitiría al visitante, observar la programación sino también participar de los bailes, comparsas, a los cuales sin duda serían invitados por la amabilidad, apertura que caracteriza a la gente provinciana tratándose de personas que no son del lugar. 
- Es un avance para interesar al asistente en conocer el lugar de origen de estas festividades, sus costumbres, gastronomía, música. La expectación de estas fiestas significa sumergirse en un mundo distinto, mágico producido por las actitudes de los oferentes que demuestran una enorme fe y esperanza en sus santos quiénes escuchan sus necesidades y accederán a sus peticiones porque ellos cumplirán con sus promesas y ofrecimientos.

Las ocho fiestas más importantes de los clubes (Patronales), estudiados en el presente trabajo, ocupan por lo menos un domingo de siete meses, si agregamos otras fiestas interesantes por su contenido, el calendario tiene 12 fiestas cuyos costos por turista serían mínimos si los comparamos con el costo de los espectáculos folclóricos o costumbristas o criollos que se dan en locales de la ciudad de Lima. Habría diferencias en cuanto a la infraestructura, calidad del servicio, elegancia pero a su favor las fiestas de clubes regionales proporcionan calor humano, mucha autenticidad en sus contenidos gastronómicos, artísticos y producen una reverencia en los foráneos que soslayan y quitan importancia a ciertas incomodidades por lo novedoso y asequible de lo que no podrían encontrar en otros sitios.

Lo auténticamente étnico que ofrecen las fiestas de los clubes regionales tienen similitud con las noches gitanas que se dan en locales tipo cuevas parecidas a las que ellos habitan en las zonas gitanas de Alicante, Granada, Almería (España), en esos escenarios se ofrecen cánticos, bailes de arte jondo que tienen una afluencia de turistas permanente llevados por las agencias de turismo que ofrecen sus tours por medio de folletería en los hoteles de 3, 4 y 5 estrellas.

Con las fiestas patronales de los clubes y otras también de gran calidad, que ofrecen permanentemente durante todo el año, se puede confeccionar un calendario preliminar que incluye las siguientes fiestas:

CALENDARIO DE FIESTAS DE CONTENIDO TURÍSTICO QUE OFRECEN LOS CLUBES REGIONALES DE LA CIUDAD DE LIMA

\begin{tabular}{lll}
\hline \multirow{2}{*}{ Febrero } & Virgen de la Candelaria & Club Puno \\
& CARNAVALES AMAZÓNICOS & Club Loreto \\
Marzo & Señor de los temblores & Club Cusco \\
Junio & San Juan Bautista & Club Loreto \\
& INTI RAIMI & Club Cusco \\
Julio & Virgen del Carmen & Club Arequipa \\
Agosto & Cruz de Chalpón & Club Lambayeque \\
Setiembre & Virgen de Cocharcas & Club Huancayo (3er domingo) \\
& Virgen del Rosario & Club Representativo Huari (4to domingo) \\
Noviembre & KERMÉS & Club Cusco \\
& ANIVERSARIO DEL CLUB & Club Huancayo \\
Diciembre & Inmaculada & Club Ancash \\
\hline
\end{tabular}

En negrita: Fiestas patronales. En mayúsculas: FIESTAS IMPORTANTES 


\section{Conclusiones}

En la ciudad de Lima existen atractivos turísticos como las festividades y la gastronomía de los clubes regionales que pueden aumentar la permanencia de los turistas en la ciudad de Lima en un día o dos días si se les proporciona la información sobre estos locales costumbristas.

La asistencia a estas fiestas étnicas no solo sería como una forma de recreación por la asistencia a los espectáculos que presentan, sino también porque son un medio para dar a conocer los atractivos de otras regiones del Perú que podrían ser de interés para viajes posteriores de estos mismos turistas o allegados a ellos.

Los clubes regionales son instituciones conservadoras y difusoras del folclor de una determinada región que no tienen fines de lucro que promueven la confraternidad entre coterráneos y según los estatutos de los clubes también incluyen a simpatizantes y colaboradores. Este espíritu abierto de la organización de los clubes hace que sus comedores sean asequibles al público en general y también sus fiestas. La presencia de turistas sería bienvenida por cuanto el espíritu provinciano es amable, generoso con los foráneos y además el consumo de los productos que ofrecen: recuerdos, bebidas, platos típicos, costo de entradas son ingresos para el mantenimiento del club.

Actualmente los clubes presentan algunas deficiencias en cuanto al servicio al cliente por tratarse de personal no calificado y algunos aspectos en el mantenimiento de sus locales pero cuando se trate de incrementar los ingresos por visitas turísticas, la reinversión los convertirá en lugares de mayor categoría.

Para lograr que se consiga popularizar estos recintos entre los turistas hace falta la intervención de las entidades oficiales de turismo y también de las empresas turísticas porque según el trabajo de campo realizado la asistencia de turistas nacionales o extranjeros no se da. Si algunos asisten a estos festejos es por invitaciones personales de socios, simpatizantes o coterráneos que no han visto mejor manera de agasajar a sus amigos o familiares que han venido del extranjero que llevarlos a los clubes regionales que conocen .

Un estudio de clubes similares a los tomados para esta muestra podrían ofrecer algunas novedades de índole turístico no conocidas porque los clubes departamentales no han sido vistos como posibilidades turísticas, solo como emporios de la peruanidad.

Se ha visto por el trabajo de campo realizado que varios clubes no pueden difundir su riqueza cultural por estar cerrados, a pesar de contar con locales adecuados para grandes reuniones festivas, hallarse en distritos de población de clase media y media alta, en los cuales sus municipalidades proporcionan seguridad, limpieza, cuidado de jardines. Esta situación puede ser atribuida a la deficiente administración pero también a la falta de ingresos.

Una relación más estrecha con la industria turística proporcionaría ingresos necesarios para un mantenimiento adecuado. 
La Ley No 29363 sobre Clubes Departamentales, Provinciales y Distritales promulgada por Alan García el 8 de mayo de 2009 en su contenido literal reafirma lo ya realizado por los clubes existentes, determina la exoneración del impuesto predial, inafectación de impuestos a las actividades de cultura y folclor y encarga a la Asociación de Clubes Departamentales del Perú, la organización y conducción de la Casa de la Peruanidad para «la difusión permanente de las expresiones genuinas de la peruanidad» (Art. 8). Asimismo, en el Art. 9, encarga al INC emitir «el reglamento correspondiente que facilite el uso de los locales del Estado destinados para ese propósito».

A través del estudio realizado en los ocho clubes, no se ha oído mencionar la existencia de la Asociación de Clubes Departamentales, y la Casa de la Peruanidad no se la conoce. Las disposiciones legislativas dadas cuando se lleven a cabo no solo cumplirán con sus fines sino que realzarán la relación entre el turismo y los clubes la Ley $N^{\circ} 29363$ lo dice: «Promover el turismo sostenible hacia sus pueblos de origen y difundir su gastronomía tradicional» (Art. 3 inciso «e»).

\section{Bibliografía recomendada}

Arguedas, J. M. (1989). Canto Kechwa: con un ensayo sobre la capacidad de creación artística del pueblo indio y mestizo. Lima: Horizonte.

CONGRESO DE LA REPÚBLICA (2009). Ley de los clubes departamentales, provinciales y distritales.

Lima. Fuller, N. (2004). Turismo y Cultura. Lima: PUCP.

Hercovits, M. (1958). El hombre y sus obras. México: FCE.

Huayhuaca, L. (2013). La Festividad del Corpus Christi en el Cusco. Lima: Ministerio de Cultura.

INEI (1994). Censos Nacionales 1993. Recuperado de http://www.censos.inei.gob.Pe/bcoCuadros/CPV93Centrospoblados.htm

Mantero, J. (julio, 2004). Turismo Cultural. Apreciaciones respecto de la actividad comentarios a propósito de Argentina. Turismo y

Patrimonio, 4, 147-162.

Merino, M. (agosto, 2003). Hacia una teoría del folcklore peruano. Wifala, 1, 49-84.

Muscari, J. (2007). Mejoramiento genético del cuy. Producción de cuyes. Lima: INIA. Ministerio de

Agricultura. Orth, M. (diciembre, 2015). María la mujer más poderosa del mundo. National Geographic,

37(6), 2-31. Pintado, C. (febrero, 2009). Aportes al folklore urbano. Boletín de Lima, 153, 137-150.

PROM PERÚ (2014). Perfil del vacacionista nacional. Lima.

PROM PERÚ - UNIÓN EUROPEA (2012). Nivel de satisfacción del turista extranjero. Lima. Quijano,

A. (1980). Dominación y Cultura. Lo cholo y el conflicto cultural en el Perú. Lima: Mosca Azul. Tito,

F. (2010). Sunchu. El huayno en la formación de la identidad. Lima.

Urbano, H. (julio, 2004). La cultura entre la tradición y modernidad. Turismo y Patrimonio, 4, 11-

20. Valcárcel, L. ( 2013 ). Ruta cultural del Perú. Lima: Entre Nous.

Venturoli, S. (2011). Los hijos de Huari. Lima: PUCP. 